\title{
Predictors for return to work after multimodal rehabilitation in persons with persistent musculoskeletal pain
}

\section{Olga Sviridova, Gunvor Gard, Peter Michaelson}

\begin{abstract}
Aims: To identify factors explaining return to work (RTW) 12 months after a multimodal rehabilitation (MMR) intervention in the REHSAM II project. Methods: The present study is a secondary assessment of the data from the randomized controlled trial REHSAM II. A total of 97 participants with persistent musculoskeletal pain were randomly allocated to MMR + web-based education or only MMR. The subjects were followed from baseline to 12 months. The baseline variables from the outcome measures were used to identify predictors. The associations between the dependent variable (i.e., RTW) and independent variables (i.e., baseline variables) were analyzed with univariate and multiple logistic regression models. Results: The univariate regression analyses showed that pain and disability level, the capacity to perform a task in relation to pain, hospital and psychiatric care, medication for insomnia, catastrophizing, self-assessed work ability compared with lifetime
\end{abstract}

Olga Sviridova ${ }^{1}$, Gunvor Gard ${ }^{2}$, Peter Michaelson ${ }^{3}$

Affiliations: ${ }^{1} \mathrm{Msc}$, Division of Health and Rehabilitation, Department of Health Sciences, Luleå University of Technology, 97187 Luleå, Sweden; ${ }^{2}$ Professor, Division of Health and Rehabilitation, Department of Health Sciences, Luleå University of Technology, 97187 Luleå, Sweden; ${ }^{3}$ Assistant Professor, Division of Health and Rehabilitation, Department of Health Sciences, Luleå University of Technology, 97187 Luleå, Sweden.

Corresponding Author: Gunvor Gard, Division of Health and Rehabilitation, Department of Health Sciences, Luleå University of Technology, 97187 Luleå, Sweden; Email: Gunvor. Gard@Itu.se

Received: 19 January 2018

Accepted: 19 March 2018

Published: 12 April 2018 best, satisfaction with life, ability for coping and controlling work situation, ability for coping with life outside work, and sense of responsibility for managing health condition were significantly associated with RTW. In the final multiple regression model, RTW was predicted by the Örebro Musculoskeletal Pain Screening Questionnaire (ÖMPSQ score) $(p=0.003$, $O R=0.961)$ and EuroQol (EQ-5D index $)(p=0.017$, $\mathrm{OR}=7.283$ ). Conclusion: Psychosocially related pain and health-related quality of life predicted RTW in the final model. The results confirm that RTW is a multidimensional problem involving a complex interaction of many factors.

Keywords: Musculoskeletal pain, Multimodal rehabilitation, Predictors, Return to work

\section{How to cite this article}

Sviridova O, Gard G, Michaelson P. Predictors for return to work after multimodal rehabilitation in persons with persistent musculoskeletal pain. Edorium J Disabil Rehabil 2018;4:100038Do5SO2018.

Article ID: 100038Do5SO2018

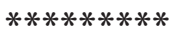

doi: 10.5348/100038Do5SO20180A

\section{INTRODUCTION}

Persistent musculoskeletal pain is common worldwide, often implying a reduced activity level, quality of life, and productivity in society due to reduced and/or lost work ability and periods of absence from work [1-4]. An extended period of absence from work is related to 


\section{EDORiUM Journals}

Edorium J Disabil Rehabil 2018;4:100038D05SO2018.

www.edoriumjournals.com/ej/dr

Olga et al. 2

a lower probability of return to work [5] and may lead to social stigmatization and economic and organizational problems on the individual, workplace, and societal levels [6]. There is a growing interest to study return to work in Sweden after the reform of the national sickness insurance system in 2008 [7]. This reform promoted a new return to work policy by focusing on early assessments of work ability, regular screening of the capacity to return to work, entitlement to benefits, and the use of evidencebased methods to return to work. The reform included also larger restrictions for receiving sickness benefits, time limits for the review of eligibility and maximum length of sick leave within the rehabilitation chain, sick leave guidelines, and a new sickness certification. The aim of these changes was to return to work within 90 days, thus reducing the number of people on sick leave [7]. The evidence that early interventions are effective for return to work is growing [8].

Return to work is an outcome measure and a goal in rehabilitation, as identifying predictors for successful return to work has a positive impact both economically and socially for individuals and society [9]. It is vital for health care specialists in their planning and optimization of effective return to work strategies [10]. The concept of RTW is often measured as employment status (i.e., as a decreased work ability, work disability, workability recovery) [11] or a return to the workplace [9]. Part-time RTW can be a pathway to full-time work [12]. To return to at least part-time work and regain one's work ability has positive consequences for the patients and is a successful RTW strategy [11].

There are different approaches when studying RTW, including identifying both risk factors for developing musculoskeletal disorders [13, 14] and predictors for RTW for persons who are suffering from musculoskeletal disorders [10, 15]. Many factors have been described in the literature as potential RTW predictors. These factors can be related to the person, the environment, and/or the workplace [10]. It has been reported that gender, age [16], a period of certified sick leave, motivation, subjective perception of pain [17], patient beliefs [18], catastrophizing [19], fear avoidance [20], and positive or negative approach to work [15] may be considered as predictors for RTW on an individual level. Workplace structure and climate, social support, development opportunities, work tasks, and relationships at work are environmental or work-related predictors [21]. Lydell et al. [8] found that the number of sick-listed days before rehabilitation, age, self-rated pain, life events, gender, physical capacity, self-rated functional capacity, educational level, and light physical labor were predictors for RTW. Positive expectations for RTW and lower disability levels have also been associated with successful RTW [1].

Few studies have analyzed success factors, i.e., factors predicting an increased return to work, after multimodal pain rehabilitation (MMR) in persons with persistent musculoskeletal disorders. There is a need to identify predictors for successful RTW in this group, as a basis for the development of effective interventions [22].

\section{REHSAM II project}

The REHSAM II project is a randomized controlled trial with the primary aim to evaluate whether MMR in combination with a web Behavior Change Program for Activity (web-BCPA) could increase work ability among persons with persistent musculoskeletal pain from the back, neck, and shoulders in primary health care as compared to MMR only. The MMR contained treatments based on a biopsychosocial perspective of pain, with the patient in focus, and included treatments from at least three health care professionals of different occupations. The multimodal rehabilitation focused on patient-centered synchronized treatments, and a cognitive behavioral approach for behavior change toward activity and participatory goals was used by the healthcare specialists. The treatment period and content were adjusted to the participants' needs and progress [23]. The intervention group also received the web-BCPA, a self-management web program to complement and improve the MMR rehabilitation. It aimed to deepen the participants' knowledge and awareness of how their pain interacted with numerous factors in their life situation in order to learn how to cope with these factors in daily life to increase activity. The web-BCPA consisted of eight modules and contained information, assignments, and exercises, assimilated via educational texts, films, and writing tasks. The participants had access to the program 24 hours a day, 7 days a week for 16 weeks.

A wide variety of outcome measures were used in the project, such as pain intensity, self-efficacy to control pain and other symptoms, self-rated health, general selfefficacy, coping, catastrophizing, among others. WebBCPA adherence and feasibility, as well as treatment satisfaction, were also investigated. The subjects were followed from baseline to 4 months and 12 months [23, 24].

There is a lack of knowledge about predictors for successful RTW after multimodal rehabilitation for persons with musculoskeletal disorders. Therefore, the aim of this study is to identify factors explaining RTW 12 months after baseline in the REHSAM II project.

\section{MATERIALS AND METHODS}

The present study is a secondary assessment of the data from a recently published randomized controlled study [24]. The baseline variables from the outcome measures included in the REHSAM II project were used to identify predictors for RTW. Data were analyzed with univariate and multiple logistic regression models. Ethical approval for the REHSAM II project was received 


\section{EDORIUM Journals}

Edorium J Disabil Rehabil 2018;4:100038D05SO2018.

www.edoriumjournals.com/ej/dr

Olga et al. 3

from The Regional Ethical Board in Umeå, Sweden (Dnr 2011-383-31M).

\section{Participants}

Participants were recruited by 17 health care centers in Norrbotten, Sweden, certified for MMR. The inclusion criteria for participants were: 1) age between 18 and 63 years; 2) persistent musculoskeletal pain with a duration of at least 3 months in back, neck, shoulder, and/or generalized pain; 3) an estimated risk for long-lasting pain conditions and future disability (score $\geq 90$ on the Örebro Musculoskeletal Pain Screening Questionnaire (ÖMPSQ); 4) work ability of at least 25\%; 5) familiarity with written and spoken Swedish; and 6) access to a computer and the Internet. Exclusion criteria were reduced cognitive ability (dementia, brain injury), current abuse of alcohol or drugs, in need of other health care (e.g., advanced medical investigation, cancer treatment, terminal care), and/or pregnancy. Participants were randomly allocated to the MMR+web group or the MMR group with opaque, numbered envelopes. The allocation sequences, separate for each health care center, were provided by an independent statistician and stratified for sex and age. The subjects were followed from baseline to 12 months.

\section{Outcome measures}

Outcome variable: In this study, RTW status was assessed as an outcome measure. In Sweden, people can work part time, depending on the assessment of the degree of work ability. Sickness benefit can be paid at 25\%, 50\%, $75 \%$, or $100 \%$ [25]. Here, we define successful RTW as maintaining same work ability level at baseline level as well as RTW to at least $25 \%$ at the 12-month follow-up compared to baseline [11, 26, 27].

Predictive variables: As there is a lack of knowledge about predictors for successful RTW after multimodal rehabilitation, we decided to include all baseline variables in the REHSAM II project in the analysis:

Background variables

- The background variables were sex, age, smoking, alcohol use, marital status, numbers of children, level of education, medication.

- Variables such as need of hospital and psychiatric care, duration of sick leave and symptoms, physical activity, work training.

- $\quad$ Treatment group (MMR or MMR+web).

Validated questionnaires measuring the following variables:

- $\quad$ Self-reported work ability - The Work Ability Index (WAI) [28].

- $\quad$ Return to work self-efficacy (RTWSE) [29].

- $\quad$ Average pain intensity during the last seven days scored on a Visual Analogue Scale (VAS) 0-100 [30].
- $\quad$ Disability - The Pain Disability Index (PDI) [31].

- Health-related quality of life - EuroQol (EQ-5D) [32].

- $\quad$ Self-efficacy and catastrophizing measures, such as the Arthritis Self-Efficacy Scale (ASES) [33].

- $\quad$ General Self-Efficacy Scale (GES) [34].

- $\quad$ Catastrophizing - Two-item Coping Strategies Questionnaire (Two-Item CSQ) [35].

- $\quad$ Physical and functional level and adjustment to injury and pain - The Örebro Musculoskeletal Pain Screening Questionnaire (ÖMPSQ) [36].

Self-constructed questions about:

- $\quad$ Coping and controlling work situation, as well as life outside work.

- $\quad$ Satisfaction with life and work, and own role in rehabilitation.

\section{Analyses}

The outcome variable, RTW, was analyzed as a dichotomous variable: as either successful or unsuccessful. The associations between the dependent variable (i.e., RTW) and each independent variable (i.e., baseline variables) were evaluated in separate univariate logistic regression models.

After that, multiple regression analyses were used to analyze the relationship between all variables being significant in the univariate logistic regression models and the dependent variable (i.e., RTW) [37].

The independent variables were included from lowest to the highest p-value from univariate analysis, and kept in the model if significant. Odds ratios (OR) were used to reflect the strength of the association. The Cox \& Snell R-square (or pseudo r-square statistic) was used to describe the approximate proportion of variation in the values of the dependent variable that could be explained by the variation in the independent variable [38].

A p-value below ( $\mathrm{p} \leq \mathrm{0.05}$ ) was considered significant. SPSS version 22.0 was used for the analysis.

\section{RESULTS}

A total of 97 participants were included in the study, 15 men and 82 women, aged between 18 and 63 years, with a mean age 42.7 (10.7) years. Of all the participants, 6o had successfully returned to work and 37 had not returned to work after 12 months, according to our definition. Within the RTW group, 30 participants were able to return to work with $25 \%$ or more compared to baseline; 30 participants continued to work at the same level.

The results of the univariate analysis are shown in Table 1. The table shows the independent variables that were significantly related to RTW.

The results of the univariate analysis showed that the EQ-5D health index, ÖMPSQ scale score, and WAI score at baseline were the most relevant variables associated with 


\section{EDORiUM Journals}

Edorium J Disabil Rehabil 2018;4:100038D05SO2018.

www.edoriumjournals.com/ej/dr

RTW after 12 months. A higher EQ-5D index indicating improved health, as well as a lower ÖMPSQ scale score at baseline indicating lower risk for developing longterm problems, were the strongest predictors related to successful RTW after 12 months. Among the other predictors, lower PDI, higher ability for coping with work and controlling work situation, and lower pain intensity last week were associated with successful RTW. Belonging to any of the treatment groups was not significantly associated with RTW outcome after 12 months.

When all factors significantly associated with RTW were entered into the multiple logistic regression, only two predictors remained significant in the final multivariable model: physical and functional level and adjustment to injury and pain, measured by the ÖMPSQ score; and quality of life, measured by the EQ-5D index (Table 2).

\section{DISCUSSION}

This study aimed to identify factors explaining RTW 12 months after baseline in the REHSAM II project.
The results showed that two variables, "Physical and functional level and adjustment to injury and pain" measured by the ÖMPSQ score, and "Self-rated health" measured by the EQ-5D index, were singled out as being associated with RTW. The ÖMPSQ instrument has been designed to predict risk for developing chronic pain associated with psychosocial factors [36, 39].

Earlier studies have shown that the ÖMPSQ has a predictive ability when pain and disability are used as an outcome in patients with low back pain [40]. The present study confirmed that the ÖMPSQ can be used as a predictor for return to work outcome. Westman et al. [41] found similar results three years after MMR for persons with non-acute musculoskeletal pain problems. Participants in their study completed MMR or a standard treatment that included a variety of treatments in primary health care. However, the researchers did not specify the procedures used or the time period for the treatment for each group. Other studies have also shown that ÖMPSQ has a predictive ability for future sick leave: the higher the score, the higher the risk for long-term sick leave [36, 39]. Based on the present results and previous studies,

Table 1: Independent variables with significant associations with return to work in univariate logistic regression.

\begin{tabular}{|c|c|c|c|}
\hline Variable & $\mathbf{P}$ & $\begin{array}{c}\text { Cox \& Snell } \\
\text { R-Square }\end{array}$ & $\begin{array}{l}\text { Odds Ratio } \\
\text { (OR) }\end{array}$ \\
\hline ÖMPSQ score & 0.000 & 0.188 & 0.952 \\
\hline EQ-5D index & 0.000 & 0.15 & 16.822 \\
\hline WAI Score & 0.000 & 0.145 & 1.332 \\
\hline PDI summary mean & 0.002 & 0.117 & 0.632 \\
\hline Satisfied with life & 0.002 & 0.112 & 1.954 \\
\hline ASES Self-efficacy symptoms summary mean & 0.004 & 0.094 & 1.039 \\
\hline Coping with work situation & 0.007 & 0.082 & 1.601 \\
\hline CSQ Catastrophizing "It is terrible and I feel it is never going to be better" & 0.008 & 0.081 & 0.626 \\
\hline Controlling work situation & 0.012 & 0.072 & 1.523 \\
\hline Psychiatric care & 0.020 & 0.096 & 0.075 \\
\hline Coping with life outside work & 0.021 & 0.06 & 1.78 \\
\hline ASES Self-efficacy pain summery mean & 0.024 & 0.055 & 1.025 \\
\hline Pain intensity minimum o-10o last week & 0.025 & 0.054 & 0.98 \\
\hline Responsible for managing my health condition $0-100$ & 0.028 & 0.054 & 1.026 \\
\hline Hospital care & 0.031 & 0.05 & 0.312 \\
\hline CSQ Catastrophizing "I feel I can't stand it anymore" & 0.033 & 0.049 & 0.741 \\
\hline Medication for insomnia last month & 0.043 & 0.042 & 0.7 \\
\hline
\end{tabular}

ÖMPSQ-The Örebro Musculoskeletal Pain Screening Questionnaire, EQ-5D- EuroQol, WAI-Work Ability Index, PDI-The Pain Disability Index, ASES - Arthritis Self-Efficacy Scale (ASES), CSQ- Coping Strategies Questionnaire

Table 2: Independent variables with significant associations with return to work.

\begin{tabular}{lccc} 
Variable & P & $\begin{array}{c}\text { Cox \& Snell } \\
\text { R Square }\end{array}$ & Odds Ratio (OR) \\
$\begin{array}{l}\text { Physical and functional level and adjustment to injury and pain } \\
\text { (ÖMPSQ score) }\end{array}$ & 0.003 & 0.240 & 0.961 \\
Self-rated health (EQ-5D index) & 0.017 & 7.283 \\
\hline
\end{tabular}

ÖMPSQ-The Örebro Musculoskeletal Pain Screening Questionnaire, EQ-5D- EuroQol 


\section{EDORIUM Journals}

Edorium J Disabil Rehabil 2018;4:100038D05SO2018.

www.edoriumjournals.com/ej/dr

Olga et al. 5

we assume that the ÖMPSQ is a promising scale for predicting RTW in rehabilitation contexts. In addition, we consider it very important to identify psychosocial risk factors for developing chronic pain as early as possible to promote early RTW. A recently developed psychosocial questionnaire, the "Blue flags questionnaire," has validated focusing on work-related psychosocial risk factors and the need for contacts and/or actions at the workplace [42].

Another predictor that was significantly associated with RTW outcome in the multiple regression analyses was self-rated health, measured by the EQ-5D instrument. Self-rated health is an often-used generic health indicator that has been examined as a predictor of subsequent disability retirement and working conditions [43].

The univariate logistic regression analysis was used to explore the association between potential predictors and RTW outcome. The results of the univariate analysis are consistent with previous studies and confirm that variables such as pain and disability level, satisfaction with life, abilities to cope with and control work situation, catastrophizing, and other psychosocial variables related to the workplace as well as outside work are related to RTW outcome [1, 14, 16, 44]. Interestingly, medication for insomnia at baseline was significantly associated with RTW in our study. To the best of our knowledge, none of the earlier studies have investigated this predictor.

A surprising finding in this study was that none of the demographic parameters, such as sex, age, or level of education, were associated with RTW. Previous studies that investigated predictors for RTW have shown that male gender [10, 16], young age [45], and higher educational status $[45,46]$ were found to be significant predictors for successful RTW after multimodal rehabilitation. A possible explanation can be difference in sample size as well as sample proportion of males and females in our study compared to other studies.

Duration of sick leave, physical activity, as well as satisfaction with present work had no association with RTW after 12 months. Number of sick-listed days before rehabilitation and physical activity have been considered as important predictors for RTW after multimodal rehabilitation in earlier studies [10, 16, 47]. Work dissatisfaction predicted non-RTW and disability in the study by Fayad et al. [48]. Return to work selfefficacy was not associated with RTW in our study, but has been mentioned in previous studies as a predictor of RTW [10]. A possible explanation may be that the multimodal rehabilitation in most of these studies focused on different work interventions to facilitate RTW in addition to MMR. In our study, no work interventions were included.

Treatment group was not associated with RTW after 12 months in our study. This means that the participants' belonging to one of the treatment groups (MMR or MMR+web) did not affect the RTW outcome. The mean use of the web-BCPA was low and may indicate that participants were not motivated by Internet therapy. Moreover, the participants in our study represented a group with severe and complex disorders. As they have experienced high pain intensity for a long time, it can be assumed that the relatively brief intervention conducted in our study could not affect RTW.

\section{Methodological considerations}

Our findings need to be discussed in light of the study limitations. First, this study was a secondary assessment of a randomized controlled trial, which is not an optimal design for investigating predictors. However, this design can be used to generate possible predictive variables for further prospective studies. Another weakness was that the large majority of participants were women, which makes it difficult to generalize the results of this study to men.

There is also an inherit risk of false positive results in the univariate regression models due to the repeated analyses, which could have affected the number of predictive models. In the final regression model, only two variables showed significant association with the outcome variable, which clearly meets the criteria for a minimum case-to-variable ratio to achieve valid results [49]. The final multiple regression model explained $24 \%$ of the variance, which indicates relatively low values of model clarification between the predictors and outcome, in comparison to Lydell et al. [10] with $25-35 \%$ of explained variance at the 5-year follow-up and $18-25 \%$ at the 10-year follow-up. Advantages of this study are that we studied a large number of different predictor variables and that almost all instruments have been widely used and have good validity and reliability.

\section{Implications and future research}

To identify predictors for successful RTW is important. It improves early identification of patients at risk for long-term sick leave and deepens the understanding of factors influencing RTW. Furthermore, it can facilitate modifiable predictors to be targeted with specific interventions and treatments and improve the planning and optimization of RTW assessment strategies, which must be considered early in the RTW process. Our study shows that the ÖMPSQ and EQ-5D instruments can be useful to identify patients with risk for long-term sick leave. However, before firm conclusions are made, prospective studies validating our findings should be performed using the ÖMPSQ and EQ-5D in a larger and heterogeneous sample.

\section{CONCLUSION}

In conclusion, psychosocially related pain and self-rated health showed an association with RTW. In 


\section{EDORiUM Journals}

addition, pain, disability, hospital and psychiatric care, medication, capacities, psychosocial factors, and work ability were related to RTW. The results confirm the fact that RTW is a multidimensional problem involving a complex interaction of many factors.

\section{REFERENCES}

1. MerrickD,Sundelin G,StålnackeBM.Anobservational study of two rehabilitation strategies for patients with chronic pain, focusing on sick leave at one-year follow-up. J Rehabil Med 2013 Nov;45(10):1049-57.

2. SBU. (The Swedish Council on Technology Assessment in Health Care). Metoder för behandling av långvarig smärta, En systematisk litteraturöversikt. 2006. [Availble at: http://www.sbu.se/contentassets/81eao 41f1bc2441aao9868a4f29d3fia/smarta_fulltext.pdf]

3. Swedish Council on health technology assessment. Methods of treating chronic Pain: A systematic review (summary and conclusions) [Internet]. Stockholm: Swedish Council on health technology assessment (SBU); 2006 Oct. SBU yellow report no. 177/1+2. [Availble at:https://www.ncbi.nlm.nih.gov/books/ NBK447986/]

4. Turk DC, Dworkin RH, Revicki D, et al. Identifying important outcome domains for chronic pain clinical trials: An IMMPACT survey of people with pain. Pain 2008 Jul 15;137(2):276-85.

5. Waddell G, Burton AK. Is Work Good for Your Health and Well-Being? London: The Stationery Office; 2006.

6. Selander J, Marnetoft SU, Bergroth A, Ekholm J. Return to work following vocational rehabilitation for neck, back and shoulder problems: Risk factors reviewed. Disabil Rehabil 2002 Sep 20;24(14):70412.

7. National Board of Health and Welfare. Försäkringsmedicinskt beslutsstöd - vägledning för sjukskrivning [Sick leave guidelines]. Swedish: Stockholm: 2007.

8. Carroll C, Rick J, Pilgrim H, Cameron J, Hillage J. Workplace involvement improves return to work rates among employees with back pain on long-term sick leave: A systematic review of the effectiveness and cost-effectiveness of interventions. Disabil Rehabil 2010;32(8):607-21.

9. Opsahl J, Eriksen HR, Tveito TH. Do expectancies of return to work and Job satisfaction predict actual return to work in workers with long lasting LBP? BMC Musculoskelet Disord 2016 Nov 17;17(1):481.

10. Lydell M, Grahn B, Månsson J, Baigi A, Marklund B. Predictive factors of sustained return to work for persons with musculoskeletal disorders who participated in rehabilitation. Work 2009;33(3):317-28.

11. de Vries HJ, Brouwer S, Groothoff JW, Geertzen $\mathrm{JH}$, Reneman MF. Staying at work with chronic nonspecific musculoskeletal pain: A qualitative study of workers' experiences. BMC Musculoskelet Disord 2011 Jun 3;12:126.

12. Blonk RWB, Brenninkmeijer V, Lagerveld SE, et al. Return to work: A comparison of two cognitive behavioural interventions in cases of work-related psychological complaints among the self-employed. Work \& Stress 2007;20(2):129-44.

13. Lincoln AE, Smith GS, Amoroso PJ, Bell NS. The natural history and risk factors of musculoskeletal conditions resulting in disability among US Army personnel. Work 2002;18(2):99-113.

14. Lötters F, Burdorf A. Prognostic factors for duration of sickness absence due to musculoskeletal disorders. Clin J Pain 2006 Feb;22(2):212-21.

15. Hansen A, Edlund C, Bränholm IB. Significant resources needed for return to work after sick leave. Work 2005;25(3):231-40.

16. Lydell M, Baigi A, Marklund B, Månsson J. Predictive factors for work capacity in patients with musculoskeletal disorders. J Rehabil Med 2005 Sep;37(5):281-5.

17. Cheng JC, Li-Tsang CW. A comparison of selfperceived physical and psycho-social worker profiles of people with direct work injury, chronic low back pain, and cumulative trauma. Work 2005;25(4):31523.

18. Crombez G, Vlaeyen JW, Heuts PH, Lysens R. Pain-related fear is more disabling than pain itself: Evidence on the role of pain-related fear in chronic back pain disability. Pain 1999 Mar;80(1-2):329-39.

19. Vlaeyen JW, Kole-Snijders AM, Boeren RG, van Eek H. Fear of movement/(re)injury in chronic low back pain and its relation to behavioral performance. Pain 1995 Sep;62(3):363-72.

20. Turner JA, Franklin G, Fulton-Kehoe D, et al. Worker recovery expectations and fear-avoidance predict work disability in a population-based workers' compensation back pain sample. Spine (Phila $\mathrm{Pa}$ 1976) 2006 Mar 15;31(6):682-9.

21. Johansson G, Lundberg O, Lundberg I. Return to work and adjustment latitude among employees on long-term sickness absence. J Occup Rehabil 2006 Jun;16(2):185-95.

22. Selander J, Marnetoft SU, Asell M. Predictors for successful vocational rehabilitation for clients with back pain problems. Disabil Rehabil 2007 Feb 15;29(3):215-20.

23. Nordin CA, Michaelson P, Gard G, Eriksson MK. Effects of the web behavior change program for activity and multimodal pain rehabilitation: Randomized controlled trial. J Med Internet Res 2016 Oct 5;18(10):e265.

24. Calner T, Nordin C, Eriksson MK, Nyberg L, Gard G, Michaelson P. Effects of a self-guided, web-based activity programme for patients with persistent musculoskeletal pain in primary healthcare: A randomized controlled trial. Eur J Pain 2017 Jul;21(6):1110-20.

25. Kristensen LE, Englund M, Neovius M, Askling J, Jacobsson LT, Petersson IF. Long-term work disability in patients with psoriatic arthritis treated with anti-tumour necrosis factor: A population-based regional Swedish cohort study. Ann Rheum Dis 2013 Oct;72(10):1675-9.

26. Löfgren M, Ekholm J, Ohman A. 'A constant struggle': Successful strategies of women in work despite fibromyalgia. Disabil Rehabil 2006 Apr 15;28(7):447- 


\section{EDORiUM Journals}

55 .

27. Wåhlin C, Ekberg K, Persson J, Bernfort L, Oberg B. Association between clinical and work-related interventions and return-to-work for patients with musculoskeletal or mental disorders. J Rehabil Med 2012 Apr;44(4):355-62.

28. Ilmarinen J. The work ability index (WAI). Occup Med 2007;57:160.

29. Shaw WS, Reme SE, Linton SJ, Huang YH, Pransky G. 3rd place, PREMUS best paper competition: Development of the return-to-work self-efficacy (RTWSE-19) questionnaire - psychometric properties and predictive validity. Scand J Work Environ Health 2011 Mar;37(2):109-19.

30. Dworkin RH, Turk DC, Farrar JT, et al. Core outcome measures for chronic pain clinical trials: IMMPACT recommendations. Pain 2005 Jan;113(1-2):9-19.

31. Tait RC, Pollard CA, Margolis RB, Duckro PN, Krause SJ. The pain disability index: Psychometric and validity data. Arch Phys Med Rehabil 1987 Jul;68(7):438-41.

32. Rabin R, de Charro F. EQ-5D: A measure of health status from the EuroQol Group. Ann Med 2001 Jul;33(5):337-43.

33. Lomi C, Nordholm LA. Validation of a Swedish version of the Arthritis Self-efficacy Scale. Scand J Rheumatol 1992;21(5):231-7.

34. Löve J, Moore CD, Hensing G. Validation of the Swedish translation of the general self-efficacy scale. Qual Life Res 2012 Sep;21(7):1249-53.

35. Jensen MP, Keefe FJ, Lefebvre JC, Romano JM, Turner JA. One- and two-item measures of pain beliefs and coping strategies. Pain 2003 Aug;104(3):453-69.

36. Linton SJ, Boersma K. Early identification of patients at risk of developing a persistent back problem: The predictive validity of the orebro musculoskeletal pain questionnaire. Clin J Pain 2003 Mar-Apr;19(2):806.

37. Carter R, Lubinsky J, Domholdt E. Rehabilitation Research: Principles and Applications. St Louis: Elsevier Saunders; 2011.

38. Cox DR, Snell EJ. Analysis of Binary Data. London: Chapman \& Hall/CRC Press; 1989.

39. Linton SJ, Halldén K. Can we screen for problematic back pain? A screening questionnaire for predicting outcome in acute and subacute back pain. Clin J Pain 1998 Sep;14(3):209-15.

40. Maher CG, Grotle M. Evaluation of the predictive validity of the orebro musculoskeletal pain screening questionnaire. Clin J Pain 2009 Oct;25(8):666-70.

41. Westman A, Linton SJ, Ohrvik J, Wahlén P, Leppert J. Do psychosocial factors predict disability and health at a 3 -year follow-up for patients with nonacute musculoskeletal pain? A validation of the orebro musculoskeletal pain screening questionnaire. Eur $\mathrm{J}$ Pain 2008 Jul;12(5):641-9.

42. Post Sennehed C, Gard G, Holmberg S, Stigmar K, Forsbrand M, Grahn B. "Blue flags", development of a short clinical questionnaire on work-related psychosocial risk factors - a validation study in primary care. BMC Musculoskelet Disord 2017 Jul 24;18(1):318.
43. Pietiläinen $\mathrm{O}$, Laaksonen $\mathrm{M}$, Rahkonen $\mathrm{O}$, Lahelma E. Self-rated health as a predictor of disability retirement - the contribution of ill-health and working conditions. PLoS One 2011;6(9):e25004.

44. Iakova M, Ballabeni P, Erhart P, Seichert N, Luthi F, Dériaz O. Self perceptions as predictors for return to work 2 years after rehabilitation in orthopedic trauma inpatients. J Occup Rehabil 2012 Dec;22(4):532-40.

45. Blackwell TL, Leierer SJ, Haupt S, Kampitsis A. Predictors of vocational rehabilitation return-to-work outcomes in workers' compensation. Rehab Couns Bull 2003;46(2):108-14.

46. Hildebrandt J1, Pfingsten M, Saur P, Jansen J. Prediction of success from a multidisciplinary treatment program for chronic low back pain. Spine (Phila Pa 1976) 1997 May 1;22(9):990-1001.

47. Grahn B, Ekdahl C, Borgquist L. Effects of a multidisciplinary rehabilitation programme on health-related quality of life in patients with prolonged musculoskeletal disorders: A 6-month follow-up of a prospective controlled study. Disabil Rehabil 1998 Aug;20(8):285-97.

48. Fayad F, Lefevre-Colau MM, Poiraudeau S, et al. Chronicity, recurrence, and return to work in low back pain: Common prognostic factors. [Article in French]. Ann Readapt Med Phys 2004 May;47(4):179-89.

49. Tabachnick BG, Fidell LS. Using Multivariate Statistics. Needham Heights: Allyn \& Bacon; 2013.

$* * * * * * * * *$

\section{Author Contributions}

Olga Sviridova - Substantial contributions to conception and design, Drafting the article, Final approval of the version to be published

Gunvor Gard - Substantial contributions to conception and design, Drafting the article, Revising it critically for important intellectual content, Final approval of the version to be published

Peter Michaelson - Substantial contributions to conception and design, Drafting the article, Revising it critically for important intellectual content, Final approval of the version to be published

\section{Guarantor of Submission}

The corresponding author is the guarantor of submission.

\section{Source of Support}

None

\section{Consent Statement}

Written informed consent was obtained from the patient for publication of this study.

\section{Conflict of Interest}

Authors declare no conflict of interest. 


\section{EDORiUM Journals}

Edorium J Disabil Rehabil 2018;4:100038D05SO2018.

Olga et al.

\section{Copyright}

(C) 2018 Olga Sviridova et al. This article is distributed under the terms of Creative Commons Attribution License which permits unrestricted use, distribution and reproduction in any medium provided the original author(s) and original publisher are properly credited. Please see the copyright policy on the journal website for more information.

\section{ABOUT THE AUTHORS}

Article citation: Sviridova O, Gard G, Michaelson P. Predictors for return to work after multimodal rehabilitation in persons with persistent musculoskeletal pain. Edorium J Disabil Rehabil 2018;4:100038Do5SO2018.

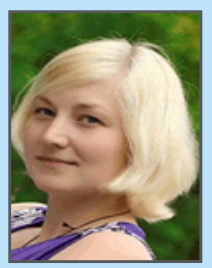

Olga Sviridova is a Physiotherapist working in primary health care in Lessebo health center, Sweden. She earned the undergraduate degree in physiotherapy from Riga Stradins University in Riga, Lettland and postgraduate degree form Master of Science in physiotherapy from Luleå University of Technology in Luleå, Sweden. Her research interests include return to work processes as well as phantom limb pain rehabilitation. She intends to pursue return to work processes and phantom limb pain rehabilitation in future. Email: schumixa@inbox.lv

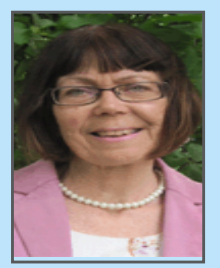

Gunvor Gard is Professor at Division of Health and Rehabilitation, Department of Health Sciences, Luleå University of Technology,Luleå,Sweden (parttime) and at the Department of Health Sciences, Lund University, Lund, Sweden. She earned the undergraduate degree (Physiotherapist) from (Karolinska Institute in Stockholm, Sweden and postgraduate degree (PhD) from (Department of Health Sciences, Luleå University of Technology, Luleå, Sweden. She has published 125 research papers in national and international academic journals and authored (4) books. Her research interests include physical and psychosocial health promotion and rehabilitation in different contexts and musculoskeletal pain rehabilitation. She intends to pursue Physical and psychosocial health promotion and rehabilitation in future.

Email: Gunvor.Gard@ltu.se

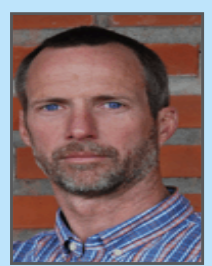

Peter Michaelson is Associate Professor at Division of Health and Rehabilitation at the Department of Health Science at Luleå University of Technology in Luleå, Sweden. He earned the undergraduate degree in physiotherapy from Umeå university, Umeå, Sweden and doctoral degree form from Sportsmedicine at Umeå University, Umeå, Sweden. He has published 16 research papers in national and international academic journals. His research interests include rehabilitation of musculoskeletal disorders and pain management. He intends to pursue musculoskeletal disorders and pain management in future.

Email: Peter.michaelson@ltu.se

Access full text article on other devices

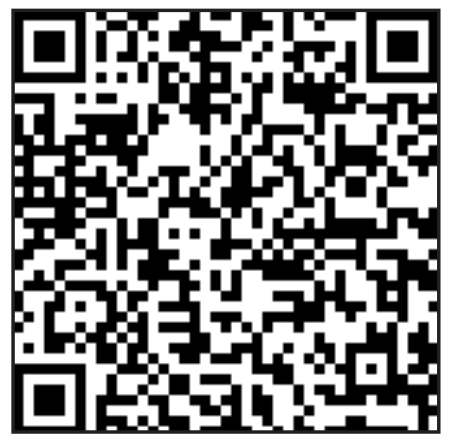

Access PDF of article on other devices

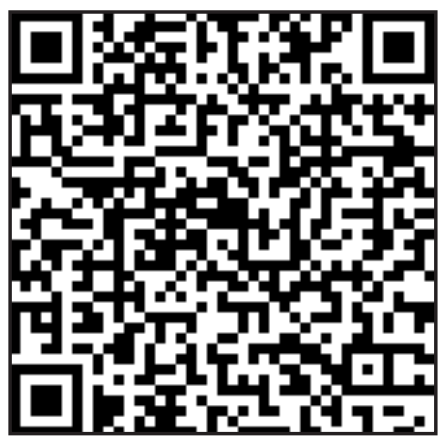

